\title{
The role of body mass index-for-age in the assessment of acute malnutrition and obesity in Moroccan hospitalized children
}

\author{
Hassan Barouaca ${ }^{1, *, \dagger}$ (D), Dalal Ben Loubir ${ }^{1}$, Bachir El Bouhali², Nabil Tachfouti ${ }^{3}$, Adil El Midaoui ${ }^{4, \dagger}$ \\ ${ }^{1}$ Higher Institute of Nursing Profession, Techniques of Health, Errachidia, Morocco. \\ ${ }^{2}$ Department of Biology, Faculty of Sciences and Techniques Errachidia, Moulay Ismail University of Meknes, Errachidia, Morocco. \\ ${ }^{3}$ Laboratoire d'Epidémiologie, Recherche Clinique et de Santé communautaire, Faculté de Médecine et de Pharmacie Fès, Fès, Maroc. \\ ${ }^{4}$ Research Team "Biology, Environment and Health," Department of Biology, Faculty of Sciences and Techniques Errachidia, Moulay Ismail University of \\ Meknes, Errachidia, Morocco.
}

\begin{tabular}{l}
\hline ARTICLE INFO \\
\hline Received on: $30 / 08 / 2020$ \\
Accepted on: 09/05/2021 \\
Available online: $05 / 07 / 2021$
\end{tabular}

\section{Key words:}

Acute malnutrition, anthropometric parameters, obesity, hospitalized children.

\begin{abstract}
The aim of the present study was to examine the accuracy of body mass index-for-age (BMI-Z), mid-upper arm circumference (MUAC), and MUAC z-score (MUAC-Z) in assessing the acute malnutrition as well as the BMI-Z in assessing obesity in Moroccan hospitalized children aged from 1 month to 5 years. This is a longitudinal observational study carried out on 337 children. Weight, height/length, and MUAC related to sex and age were determined at admission and exported to World Health Organization (WHO) Anthro software for conversion to sex-age specific z-score indices. Weighted Cohen's Kappa test was used to assess the concordance between weight-for-height z-score (WFH-Z), BMI-Z, MUAC-Z, and MUAC in screening for acute malnutrition defined as WFH-Z $<-2 \mathrm{SD}$ or between WFH-Z and BMI-Z in screening for obesity as defined by WFH-Z $>3$ SD. The area under the receiver operating characteristic (ROC) area under the curve (AUC) was used to assess the performance of the anthropometric indexes in screening for acute malnutrition. We found high malnutrition prevalence as reflected by wasting (12.17\%), stunting $(13.35 \%)$, overweighting risk $(24.64 \%)$, overweighting $(11.39 \%)$, and low malnutrition prevalence as indicated by underweighting $(4.75 \%)$ and obesity $(3.56 \%)$. The BMI-Z showed perfect agreement to diagnose acute malnutrition $($ Kappa $=0.872)$ and obesity $($ Kappa $=0.827)$ with higher sensitivity and specificity indexes as well as higher positive predictive and negative predictive values. The AUC of the BMI-Z revealed very outstanding diagnostic accuracy to assess acute malnutrition $(\mathrm{AUC}=0.98)$ and obesity $(\mathrm{AUC}=0.99)$ in comparison to those of MUAC $(\mathrm{AUC}=0.75)$ and MUAC-Z (AUC $=0.69)$. The results of the present study suggest that BMI-Z could be a good alternative indicator to assess acute malnutrition and obesity in hospitalized children aged from 1 month to 5 years.
\end{abstract}

\section{INTRODUCTION}

It is estimated that undernutrition is still responsible as an underlying factor for nearly half of deaths among children under 5 years [Black et al., 2013; World Health Organization, United Nations Children's Fund (UNICEF), 2019]. Developing countries are called upon to confront and address the challenge of both increased obesity (Black et al., 2013) and the persistence

\footnotetext{
${ }^{*}$ Corresponding Author

Hassan Barouaca, Higher Institute of Nursing Profession, Techniques of Health,Errachidia, Morocco.E-mail: barouaca@yahoo.fr

these authors contributed equally to this work.
}

of acute malnutrition as a major health burden (Müller, and Krawinkel, 2005). In health care settings, malnutrition is considered a common finding encountered during hospitalization, particularly in pediatric words (Joosten and Hulst, 2011). The malnutrition may be aggravated by inadequate practices such as the lack of nutritional screening. Indeed, the Academy of Nutrition and Dietetics and American Society for Parenteral and Enteral Nutrition recommend the assessment of pediatric malnutrition in the hospital setting (Becker et al., 2014; Mehta et al., 2013). The WHO recommends the use of conventional nutritional tools, based on growth standards to assess malnutrition (WHO, 2006). These tools are $\mathrm{z}$-score indices based on weight, height/length, and z-score Mid-Upper Arm Circumference (MUAC) adjusted by age and sex. This nutritional assessment was largely used in 
both the communities and health settings and at the individual clinical level. Meijers et al. (2010) emphasized the complexity in defining malnutrition which makes the establishment of an appropriate method more complicated which is able to assess the nutritional status and thus to determine adequately the prevalence of malnutrition in children under 5 years. The reviewed literature showed that the prevalence of malnutrition in hospitalized children is highly variable in developed and developing countries' oscillating between $6 \%-37 \%$ and $6.1 \%-31.8 \%$ depending on the diagnostic criteria, respectively (Daskalou et al., 2016; Marginean et al., 2014; Pawellek et al., 2008; Hankard et al., 2001; Öztürk et al., 2003). Becker et al. (2014) reported that the variation in the prevalence of malnutrition is due to the variability of the diagnostic tools and their cut-off points. Consequently, it is difficult to determine the exact malnutrition prevalence because of the lack of standardized diagnostic criteria. Studies have confirmed that malnutrition prevalence differences are explained by the significant variations in the anthropometric parameters used notably between WFH-Z and MUAC (Bilukha and Leidman, 2018; Dukhi et al., 2017) or MUAC Z-score (MUAC-Z) and MUAC (Leidman et al., 2019). Moreover, in Morocco, malnutrition is qualified as a public health problem, despite efforts devoted by the government during the last five decades to fight the children undernutrition (Barouaca, 2012). In addition, the household survey results (ENPSF, 2018) showed a notable improvement in children undernutrition with the emergence of overweighting and obesity and the persistence of micronutrient deficiencies, particularly in children under 5 years. It is noteworthy that the cost of health and the loss of citizen productivity linked to malnutrition and micronutrient deficiencies represent a waste of $5 \%$ of the Moroccan Gross Domestic Product (Ministère de la Santé, 2012). According to the Ministry of Health Data, endocrine, nutritional, and metabolic diseases as well as severe acute malnutrition are classified as the important causes of hospital morbidity by $7.1 \%$ and $0.9 \%$, respectively (Ministère de la Santé, 2012). Furthermore, even if the primary malnutrition prevalence was found to be decreased at the community level in children under 5 years (ENPSF, 2018), its impact on hospital pediatric care settings is still unknown. Therefore, the paucity of data on the nutritional status of children at admission or at risk of malnutrition in Moroccan hospitals prompted us to set up this study. Thus, the goal of this study was to assess the malnutrition prevalence in Moroccan children under 5 years admitted to the regional hospital. In addition, the aim of the present study was to provide an answer to this variability in the prevalence of malnutrition by analyzing the agreement between the WFH-Z, body mass index-for-age (BMI-Z), MUAC, and MUAC-Z in the assessment of acute malnutrition and the BMI-Z for obesity.

\section{METHODS}

\section{Design}

We performed a longitudinal observational study between February 1, 2018, and May 30, 2019.

\section{Setting}

The survey was carried out in the pediatric unit of the Moulay Ali Chérif Regional Hospital Center, Errachidia City. This regional hospital is located in the Drâa-Tafilalet region, in the
Southeast of Morocco. The population of this region is recognized by its low socioeconomic background since the urban and rural areas are affected by poverty with $14.5 \%$ and $19.5 \%$, respectively. The economic activities are essentially based on agriculture $(90 \%)$ and related activities (MIDGCL, 2015).

\section{Inclusion and exclusion criteria}

All children admitted to pediatric wards for at least 48 hours and aged from 1 to 60 months were eligible to participate in the study. Exclusion criteria include the patients' age of less than 1 month, with birth weight less than $2,500 \mathrm{~g}$ or prematurity history and the refusal of the guardian or children's parents to participate in the study.

\section{Data collection}

Data were collected using a structured questionnaire that comprises items on sociodemographic characteristics and anthropometric measures. The admission diagnosed diseases and analysis biological results were collected from the medical files of each participant. The anthropometric measurements notably weight, height, or length (for children aged $\leq 2$ years, MUAC) were taking upon admission. The participants were weighted with no shoes and minimum clothing by using a calibrated digital scale (KINLEE-20, precision $5 \mathrm{~g}$ ). For infants/toddlers (age $\leq 2$ years), the weight was taken without clothes and nappies while the length was measured with infant-meter to the nearest millimeter. In children who can stand, the height was measured with a wall-mounted stadiometer to the nearest millimeter. The MUAC was measured with plastic tape to the nearest $0.1 \mathrm{~cm}$. The anthropometric measures, related to sex and age (month) of each child, were then exported to WHO Anthro software (version 3.2.2) and converted into specific sex-age z-score of conventional indices of malnutrition. The results in $\mathrm{Z}$-score values are based on WHO growth standards for children between birth and 60 months (WHO, 2006). The nutritional status was assessed by conventional classification of anthropometric indices [weight-forage z-score (WFA-Z), height-for-age z-score (HFA-Z), WFH-Z, BMI-Z, MUAC, and MUAC-for-age (MUAC-Z)] according to the WHO cut-off points (De Onis, 2015). All these conventional classifications were used to assess the prevalence of malnutrition defined as severe wasting (WFH-Z $<-3 \mathrm{SD}$, MUAC-Z $<-3 \mathrm{SD}$, and MUAC $<11.5 \mathrm{~cm}$ ); wasting (or acute malnutrition, WFH-Z $<-2 \mathrm{SD}$ and MUAC $<12.5 \mathrm{~cm}$ ); severe underweight (WFA-Z $<$ $-3 \mathrm{SD}$ ); underweight (WFA-Z $<-2 \mathrm{SD}$ ); severe stunting (chronic malnutrition, HFA-Z $<-3 \mathrm{SD}$ ); stunting (HFA-Z $<-2 \mathrm{SD}$ ); severe undernutrition (MUAC-Z $<-2 \mathrm{SD}$ ); undernutrition (MUAC-Z $<-1 \mathrm{SD}$ ); risk of overweight (BMI-Z > 1SD; WFH-Z > 1SD); overweight (BMI-Z $>2 \mathrm{SD}$; WFH-Z $>2 \mathrm{SD})$; and obese (WFH-Z $>$ $3 \mathrm{SD}$; BMI-Z > 3SD). Data were collected following the enrollment process performed by two trained nurses with the introduction of a face-to-face anonymous questionnaire to the parents.

\section{Data management}

The data were entered and double-checked in Excel software and then analyzed by the MedCal ${ }^{\circledR}$ (version 9.3.0.0, http://www.medcal.be). To compare the mean differences between groups, Student's T-test was used. The chi-square test was used to compare the gender groups and to compare the prevalence 
levels driven by the two anthropometric indices. Cohen's Kappa coefficient was used to assess the degree of agreement between WFH-Z and BMI-Z, MUAC-Z, and MUAC in screening acute malnutrition or between WFH-Z and BMI-Z to screen for obesity (Cohen, 1968). The Kappa values were interpreted in accordance with scores proposed by Landis and Koch (1977) for the strength of agreement: no agreement $(<0)$; poor agreement $(0-0.19)$; mild agreement $(0.20-0.39)$; moderate agreement $(0.40-0.59)$; substantial agreement (0.60-0.79); and almost perfect agreement $(0.80-1.00)$. The $p$-value $(p<0.05)$ was considered to be statistically significant for all tests. The ROC plots were used to examine the accuracy of a diagnostic test (Zweig and Campbell, 1993; Hanley and McNeil, 1982). The ROC plots the sensitivity against the 1-specificity across a range of values of BMI-Z, MUAC, and MUAC-Z to assess their diagnostic performance for acute malnutrition. The validity was evaluated by the sensitivity, specificity, positive predictive value (PPV), and negative predictive value (NPV) of each test (Parikh et al., 2008). The area under the ROC curves (AUC) values of 0.5 suggests no discrimination, $0.7-0.8$ is considered acceptable, from 0.8 to 0.9 is considered excellent, and more than 0.9 is suggesting very outstanding accuracy (Hosmer and Lemeshow, 2000).

\section{Regulatory and ethical aspects}

The goal of the study was explained in detail to children's parents or guardians with the use of local language before beginning the process of patient's selection. The permission to conduct the study was obtained from the Errachidia Regional Health Directorate and from the director of Moulay Ali Chrif Hospital. This study was approved by the local medical ethics committee from the Health Ministry of Morocco, regional direction of DrâaTafilalet, under the ethical approval number: 04-07-17-285. The written informed consent was obtained from the participant guardian or children's parent by preserving confidentiality with respect to Helsinki declaration guidelines (World Medical Association, 2013). Participation or refusals did not affect the medical treatment of the children during their hospital stay.

\section{RESULTS AND DISCUSSION}

Three hundred thirty-seven children were enrolled in the present survey with the mean age of 16.5 months \pm 14.74 (Table 1). As shown in Table 2, the overall prevalence of wasting (acute malnutrition) in the 337 admitted children as represented by the WFH-Z $<-2$ SD, MUAC $<12.5 \mathrm{~cm}$, MUAC-Z $<-2 \mathrm{SD}$, and BMI-Z $<-2$ SD was $41(12.17 \%), 28(8.30 \%), 18(5.71)$, and 49 (14.54\%), respectively. The prevalence of severe wasting (acute malnutrition) as depicted by WFH-Z $<-3 \mathrm{SD}, \mathrm{MUAC}<11.5 \mathrm{~cm}$, MUAC-Z $<-3$ SD, and BMI-Z $<-3$ SD was 14 (4.15\%), $8(2.37 \%)$, $4(1.27 \%)$, and $14(4.15 \%)$, respectively, with higher values in females compared to male participants for WFH-Z and BMI-Z. Severe underweight prevalence as indicated by WFA-Z $<-3$ SD was low $4(1.19 \%)$ with significantly $(<0.0001)$ higher values in female compared to male participants. The overall prevalence of stunting as indicated by HFA-Z $<-2 \mathrm{SD}$ was 45 (13.35\%), whereas its severe form was $18(5.34 \%)$ with higher values in the females compared to male patients for its severe form. As shown in Table 2 , we have found that the prevalence of obesity (BMI-Z $>3 \mathrm{SD}$ or WFH-Z > 3SD) was $12(3.56 \%)$ with higher values in males
Table 1. Characteristics and anthropometric parameters in admitted hospitalized children.

\begin{tabular}{lccc}
\hline Characteristics & Boys & Girls & $\boldsymbol{p}$-value \\
\hline Gender, $n$ (\%) & $179(53.11)$ & $158(46.88)$ & NS \\
Mean age (months) & $16.75 \pm 14.14$ & $16.42 \pm 15.46$ & NS \\
Age group (months \pm SD) & & & \\
$1-11$ & $5.99 \pm 2.876$ & $5.33 \pm 2.62$ & NS \\
$12-35$ & $19.62 \pm 6.619$ & $19.53 \pm 6.19$ & NS \\
36-60 & $43.64 \pm 7.217$ & $45.96 \pm 8.36$ & NS \\
Anthropometric parameters & & & \\
Weight (kg) & $10.14 \pm 3.24$ & $9.37 \pm 3.33$ & 0.03 \\
Higher or length (cm) & $77.88 \pm 13.11$ & $75.75 \pm 14.34$ & NS \\
MUAC (cm) & $15.704 \pm 2.17$ & $15.39 \pm 2.32$ & NS \\
WFH-Z & $-0.045 \pm 1.728$ & $-0.082 \pm 1.579$ & NS \\
WFA-Z & $-0.089 \pm 1.182$ & $-0.059 \pm 1.097$ & NS \\
HFA-Z & $0.081 \pm 1.982$ & $0.177 \pm 1.986$ & NS \\
MUAC-Z & $0.867 \pm 1.698$ & $0.799 \pm 1.788$ & NS \\
BMI-Z & $-0.157 \pm 1.752$ & $-0.188 \pm 1.596$ & NS \\
\hline
\end{tabular}

Data are means $\pm \mathrm{SD}$.

$\mathrm{NS}=$ not significant

Table 2. Overall prevalence of malnutrition by gender at admission based on conventional cut-off point's standard of WHO reference.

\begin{tabular}{ccccc}
\hline $\begin{array}{c}\text { Cut-off classification } \\
\text { of malnutrition }\end{array}$ & $\begin{array}{c}\text { Overall } \\
\text { prevalence, } \\
\boldsymbol{n}(\boldsymbol{\%})\end{array}$ & $\begin{array}{c}\text { Female, } \boldsymbol{n} \\
(\boldsymbol{\%})\end{array}$ & Male, $\boldsymbol{n}(\mathbf{\%})$ & $\boldsymbol{p}$ \\
\hline WFH-Z $<-2 \mathrm{SD}^{\mathrm{a}}$ & $41(12.17)$ & $17(5.04)$ & $24(7.12)$ & 0.701 \\
MUAC $<12.5 \mathrm{~cm}^{\mathrm{a}}$ & $28(8.30)$ & $16(12.74)$ & $12(12.56)$ & 0.575 \\
MUAC-Z $<-2 \mathrm{SD}^{\mathrm{a}}$ & $18(5.71)$ & $5(3.40)$ & $13(7.74)$ & 0.464 \\
BMI-Z $<-2 \mathrm{SD}^{\mathrm{a}}$ & $49(14.54)$ & $22(6.53)$ & $27(8.01)$ & 0.724 \\
WFH-Z $<-3 \mathrm{SD}^{\mathrm{b}}$ & $14(4.15)$ & $3(0.89)$ & $11(3.26)$ & 0.077 \\
MUAC $<11.5 \mathrm{~cm}^{\mathrm{b}}$ & $8(2.37)$ & $6(1.78)$ & $2(0.59)$ & 0.001 \\
MUAC-Z $<-3 \mathrm{SD}^{\mathrm{b}}$ & $4(1.27)$ & $3(0.67)$ & $1(0.60)$ & $<0.0001$ \\
BMI-Z $<-3 \mathrm{SD}^{\mathrm{b}}$ & $14(4.15)$ & $4(1.19)$ & $10(2.97)$ & 0.078 \\
WFA-Z $<-3 \mathrm{SD}^{\mathrm{c}}$ & $4(1.19)$ & $3(0.89)$ & $1(0.3)$ & $<0.0001$ \\
WFA-Z $<-2 \mathrm{SD}^{\mathrm{d}}$ & $16(4.75)$ & $17(5.04)$ & $11(3.26)$ & 0.469 \\
HFA-Z $<-2 \mathrm{SD}^{\mathrm{e}}$ & $45(13.35)$ & $20(5.93)$ & $25(7.42)$ & 0.689 \\
HFA-Z $<-3 \mathrm{SD}^{\mathrm{e}}$ & $18(5.34)$ & $5(1.48)$ & $13(0.89)$ & 0.013 \\
WFH-Z $>3 \mathrm{SD}^{\mathrm{f}}$ & $12(3.56)$ & $4(1.19)$ & $8(2.37)$ & 0.039 \\
BMI-Z $>3 \mathrm{SD}^{\mathrm{f}}$ & $12(3.56)$ & $4(1.19)$ & $8(2.37)$ & 0.039 \\
WFH-Z $>2 \mathrm{SD}^{\mathrm{g}}$ & $35(11.39)$ & $15(4.45)$ & $20(5.93)$ & 0.569 \\
BMI-Z $>2 \mathrm{SD}^{\mathrm{g}}$ & $32(9.50)$ & $13(3.86)$ & $19(5.64)$ & 0.546 \\
WFH-Z $>1 \mathrm{SD}^{\mathrm{h}}$ & $81(24.03)$ & $38(11.28)$ & $43(12.76)$ & 0.890 \\
BMI-Z $>1 \mathrm{SD}^{\mathrm{h}}$ & $82(24.33)$ & $38(11.28)$ & $44(13.06)$ & 0.926 \\
\hline
\end{tabular}

Mid-Upper-Arm-Circumference z-score is calculating only for age of 3-60 months.

${ }^{a}$ Wasting (acute malnutrition).

${ }^{b}$ Severe wasting (acute malnutrition).

'Underweighting.

dSevere underweighting.

'Stunting; severe stunting.

fObese.

goverweighting.

hisk of overweighting.

Difference was considered statistically significant between boys and girls values when $p$ $<0.05$. 
compared to females $(p=0.039)$. From the overall children, 40 (10.39\%) were considered overweight when expressed by WFH-Z $>2 \mathrm{SD}$ and $32(9.50 \%)$ as expressed by BMI-Z $>2 \mathrm{SD}$. The prevalence of the overweight risk depicted either by BMI-Z $>1 \mathrm{SD}$ and WFH-Z $>1$ SD was similar (82 (24.33) and 81 (24.03)) and was higher than all studied prevalence patterns (Table 2).

Table 3 displays the assessment of the agreement between the anthropometric indices assessed by Cohen's Kappa coefficient and their respective diagnostic accuracy evaluated by the ROC curve. A higher level of agreement was achieved between BMI-Z and WFH-Z in assessing acute malnutrition $($ Kappa $=0.872)$ and obesity $($ Kappa $=0.827)$. The ROC curve of BMI-Z was found to have an excellent performance ability with higher sensitivity and specificity to discriminate children with acute malnutrition and obesity (Fig. 1).

To the author's knowledge, this study is the first to describe in detail the malnutrition prevalence by using standard nutritional assessment tools in Moroccan children aged from 1 month to 5 years at admission to the hospital. Our overall undernutrition prevalence of wasting (WFH-Z $<-2 \mathrm{SD}$ ), underweighting (WFA-Z $<-2 \mathrm{SD}$ ), and stunting (HFA-Z $<-2 \mathrm{SD}$ ) were $12.17 \%, 4.75 \%$, and $13.35 \%$, respectively. The high prevalence observed in the present study in wasting, underweight, and stunting parameters [WFH-Z < -2SD (12.17\%); WFA-Z < -2SD (4.75\%); HFA-Z < $-2 \mathrm{SD}(13.35 \%)]$ showed clearly that children at admission to the health care setting were more undernourished than community children at the national $(2.6 \%, 2.9 \%$, and $15.1 \%)$ or at the urban level $(2.5 \%, 2.0 \%$, and $10.4 \%)$, respectively (ENPSF, 2018). The wasting malnutrition prevalence found in the present study is in accordance with that from previous studies (Moy et al., 1990; Sissaoui et al., 2013) and lower (27.7\%) than that reported by Doğan et al. (2005) in regional Turkish hospitals. In the results of the present study, although there was a tendency toward an increase in malnutrition prevalence between males and females,

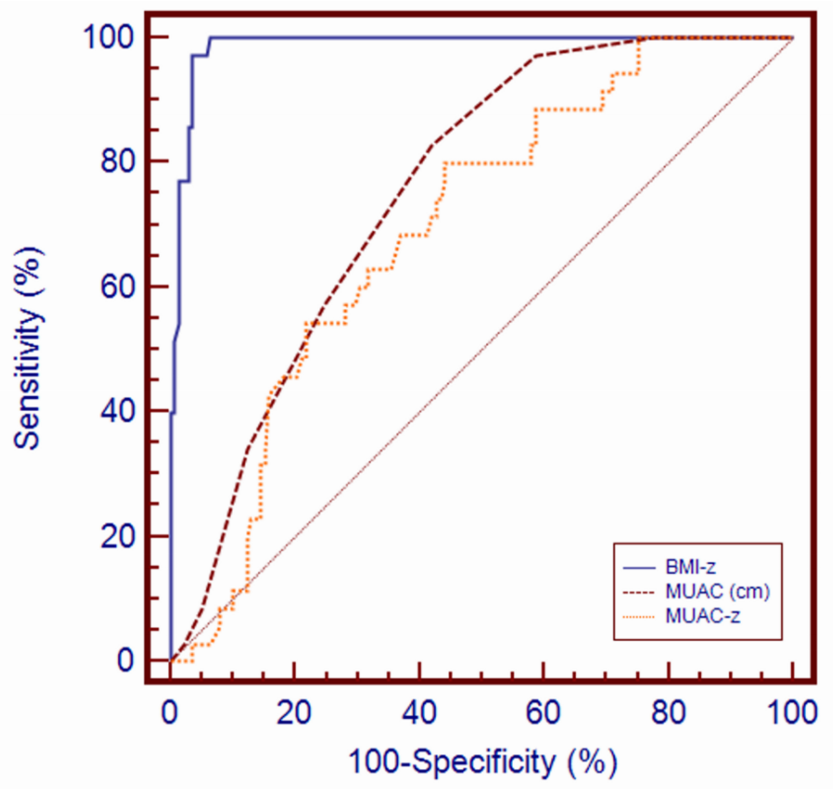

Figure 1. The ROC curves plotting to compare the diagnostic ability of BMI-Z, MUAC-Z, and MUAC in assessing acute malnutrition. the difference remains not statistically significant. The fact that the data of the present study revealed high stunting prevalence $(13.35 \%)$ proves the endemic persistence of chronic children malnutrition despite effort consented by the Moroccan government during the last five decades (Ministère de la Santé, 2011).

More interestingly, we have found that $3.56 \%$ of children as determined by BMI-Z $>3$ SD or WFH-Z $>3$ SD were obese and $24 \%$ were at risk of overweight as depicted either by WFH-Z $>1 \mathrm{SD}$ or BMI-Z > 1SD, whereas the overweight prevalence was typically $9.50 \%$ as indicated by BMI-Z $>2 \mathrm{SD}$ and $11.39 \%$ as represented by WFH-Z $>2 \mathrm{SD}$ at admission to the hospital. The prevalence of obesity observed in the present study is in agreement with that reported previously (ENPSF, 2018). The prevalence of overweight is equivalent to that found at both the national level $(10.8 \%)$ and Drâa-Tafilalet region $(9.8 \%)$. In terms of epidemiological relevance, the coexistence of the high prevalence of wasting (12.17\%) and stunting $(13.35 \%)$ simultaneously with a high prevalence of overweighting $(9.50 \%)$ and obesity $(3.56 \%)$ associated with micronutrient deficiencies (Ministère de la Santé, 2011) may prove the triple burden of malnutrition and could be considered as a serious health problem (WHO, 1995). This paradox situation is challenging health professionals to prioritize the care for malnutrition, as Morocco was engaged in the Sustainable Development Goals, set by the United Nations in 2015 in identifying, preventing, and controlling noncommunicable diseases.

WHO recommended the utilization of MUAC or WFH-Z in the assessment of acute malnutrition (WHO, 2013). However, in the present study, we have found that there was heterogeneity in acute malnutrition prevalence between the MUAC and WFH-Z. The prevalence of moderate wasting $28(8.30 \%)$ as depicted by MUAC $<12.5 \mathrm{~cm}$ was quite lower than that of $41(12.70 \%)$ as indicated by WFH-Z $<-2 \mathrm{SD}$. In the same way, the severe wasting prevalence of $8(2.37 \%)$ as depicted by MUAC $<11.5 \mathrm{~cm}$ was clearly lesser than that of $14(4.15 \%)$ as indicated by WFH-Z < $-3 \mathrm{SD}$. Interestingly, the BMI-Z $<-3 \mathrm{SD}$ value $[14(4.15 \%)]$ was found to be equivalent to that of WFH-Z $<-3$ SD [14 (4.15\%)]. These results are in concordance with those reported previously (Dukhi et al., 2017; Wieringa et al., 2018). In fact, the present study demonstrates disagreement between the WFH-Z, MUAC, and MUAC-Z as indicated by the Kappa indices (Kappa (WFH-Z vs. $\mathrm{MUAC})=0.019$; Kappa $(\mathrm{WFH}-\mathrm{Z}$ vs. MUAC-Z) $=-0.041)$ in assessing acute malnutrition (Table 3). These results are in agreement with those reported previously (Bélanger et al., 2019; Bilukha and Leidman 2018; Hossain et al., 2017; Tadesse et al., 2017). This variation in malnutrition prevalence was also present

Table 3. Agreement between WFH-Z and MUAC, BMI-Z, and MUAC-Z in assessing the acute malnutrition and obesity for BMI-Z.

\begin{tabular}{cccc}
\hline \multirow{2}{*}{ Nutritional indices } & \multicolumn{3}{c}{ Value of Cohen's Kappa concordance } \\
\cline { 2 - 4 } & BMI-Z & MUAC-Z & WFH-Z \\
\hline MUAC $<12.5 \mathrm{~cm}$ & 0.056 & 0.588 & 0.019 \\
BMI-Z $<-2 \mathrm{SD}$ & $*$ & -0.017 & 0.872 \\
MUAC-Z $<-2 \mathrm{SD}$ & $*$ & $*$ & -0.041 \\
BMI-Z $>3 \mathrm{SD}$ & $*$ & $*$ & 0.827 \\
\hline
\end{tabular}


Table 4. Diagnostic performance of BMI-Z, MUAC, and MUAC-Z in screening the acute malnutrition and obesity for the BMI-Z.

\begin{tabular}{cccccc}
\hline Nutritional indices & AUC (95\% CI) & Sens. (95\% CI) & Spec. (95\% CI) & PPV & NPV \\
\hline BMI-Z $<-2$ SD & $0.98(0.95-0.99)$ & $100.0(91.9-100.0)$ & $99.28(96.0-99.9)$ & 97.8 & 100.0 \\
MUAC $<12.5$ cm & $0.75(0.68-0.81)$ & $34.21(19.6-51.4)$ & $84.83(77.9-90.2)$ & 37.1 & 83.1 \\
MUAC-Z $<-2$ SD & $0.69(0.62-0.76)$ & $5.71(0.9-19.2)$ & $92.09(86.3-96.0)$ & 15.4 & 79.5 \\
BMI-Z $>$ 3SD & $0.99(0.97-0.99)$ & $80.00(42.8-94.2)$ & $98.88(96.0-99.8)$ & 66.7 & 99.4 \\
\hline
\end{tabular}

AUC: area under the curve; CI: confidence interval; Sens.: sensibility; Spec.: specificity: PPV: positive predictive value; NPV: negative predictive value.

between the group's genders. The present study shows that severe wasting prevalence in males and females is higher when represented by WFH-Z $<-3 \mathrm{SD}(3.26 \%$ and $0.89 \%)$ in comparison to that indicated by MUAC $<11.5 \mathrm{~cm}(0.59 \%$ and $1.78 \%)$, respectively (Table 2). These results are in concordance with previous studies (Tessema et al., 2020). Hence, the use of MUAC $<11.5 \mathrm{~cm}$ overlaps $50 \%$ of male with severe wasting when compared to WFH-Z $<$ $-3 \mathrm{SD}$. These results are in concordance with those of Grellety and Golden (2016). It is known that MUAC is an easy and preferred tool to assess global moderate/severe acute malnutrition in the community (Sachdeva et al., 2016). However, Fiorentino et al. (2016) have reported that MUAC is not convincing as a single criterion to screen the real prevalence of either moderate or severe acute malnutrition. Moreover, the fact that our results showed that malnutrition prevalence as represented by MUAC values is lower than that indicated by WFH-Z $<-3 \mathrm{SD}$ or WFH-Z $<-2 \mathrm{SD}$ may suggest that undernourished children could be undiagnosed. Thus, one may miss to determine the real malnutrition prevalence and therefore to treat those vulnerable patients which could lead to an increased risk of death.

Until now, there are no single tools that have been fixed for childhood to adulthood pediatric malnutrition. In this optic, McCarthy et al. (2019) pointed out the lack of consistency in the type of tools and their cut-off limits in assessing the extent of malnutrition prevalence. Meijers et al. (2010) argued that there is a debate on the most appropriate and suitable criteria to define malnutrition. The lack of consistency in the type of measures and their cut-off values prevents estimating the true prevalence of the overall burden of malnutrition in children. However, this heterogeneity in the measures of the prevalence of malnutrition reminds us and forces us not only to standardize the indicators of the diagnosis of pediatric malnutrition that we apply but also to refine the thresholds of malnutrition in order to maximize our ability to correctly identify and prevent missing treatment of malnutrition children at high-risk death. In this context, the BMI-Z seems to ensure the coherence in malnutrition prevalence from birth to adulthood, to avoid the weakness of anthropometric indices and thus the heterogeneity in malnutrition prevalence. Indeed, the WHO has updated the BMI-for-age growth reference, by the inclusion of children $<2$ years (WHO, 2006). As indicated in Table 3, the BMI-for-age and WFH-Z give an equal prevalence in assessing acute malnutrition or obesity with a perfect agreement to diagnose acute malnutrition (BMI-Z $<-2 \mathrm{SD}$, Kappa $=0.872$ ) and obesity $(\mathrm{BMI}-\mathrm{Z}>3 \mathrm{SD}$, Kappa $=0.827)($ Table 3$)$. These results are in accordance with the findings of Furlong et al. (2016) which showed that BMI and WFH-Z present high agreement in the determination of acute malnutrition. In addition, Zong et al. (2017) have reported that BMI and WFH-Z indicators present high concordance in the assessment of wasting, overweight, and obesity.
In the present study, we have found a perfect agreement between WFH-Z and BMI-Z as reflected by the very outstanding diagnostic accuracy (AUC $=0.98$ ) for acute malnutrition and $(\mathrm{AUC}=0.99)$ for obesity (Table 4$)$. Moreover, the high sensitivity and specificity indices as well as high PPV and NPV values (Table 4) support the idea that the BMI-Z may be considered as a suitable indicator for acute malnutrition and obesity. These results are in agreement with those reported previously Chiabi et al. (2017). Hence, we suggest that, in clinical practices, the use of BMI-Z may facilitate the assessment of atypical growth patterns (wasting and obesity) from the birth to adulthood. This may avoid interand intravariability in malnutrition prevalence, facilitating the comparison and preventing the rising incidence of obesity in early life which reached alarming proportions in many countries $(\mathrm{Ng}$ et al., 2013). Thus, we think to consider the BMI-for-age as a suitable and feasible indicator to assess the overall prevalence of wasting and obesity in children under 5 years.

\section{CONCLUSION}

The results of the present study showed that Moroccan children under 5 years from Drâa-Tafilalet area present high malnutrition prevalence as reflected by wasting (12.17\%), stunting (13.35\%), overweighting risk $(24.64 \%)$, overweighting $(11.39 \%)$, and low malnutrition prevalence as underweighting $(4.75 \%)$ and obesity $(3.56 \%)$. The BMI-Z showed perfect agreement to diagnose acute malnutrition (Kappa $=0.872$ ) and obesity $($ Kappa $=0.827)$ with higher sensitivity and specificity indexes as well as higher positive PPV and NPV. The present study also demonstrated that AUC of the BMI-Z presented very outstanding diagnostic accuracy to assess acute malnutrition $(\mathrm{AUC}=0.98)$ and obesity (AUC $=0.99$ ) in comparison to those of MUAC $(A U C=0.75)$ and MUAC-Z $(A U C=0.69)$. Thus, the present study suggests that BMI-Z could be a good alternative indicator to assess acute malnutrition and obesity in children aged from 1 month to 5 years. These findings emphasize that high children malnutrition prevalence observed in Drâa-Tafilalet region may place responsibility on clinical providers to identify, intervene, and prevent malnutrition early, with locally appropriate measures in the pediatric care setting.

\section{ACKNOWLEDGMENTS}

The authors would like to thank all participating children and their parents for taking part in this study and the dietician and physicians for their cooperation.

\section{AUTHOR'S CONTRIBUTION}

Hassan Barouaca conceived and designed the study. Hassan Barouaca and Adil El Midaoui analyzed the data. Nabil Tachfouti, Bachir El Bouhali, and Dalal Ben Loubir contributed 
to the discussion of the manuscript. Hassan Barouaca drafted the paper. Adil El Midaoui edited the final version of the paper. All authors approved the final manuscript.

\section{DATA AVAILABILITY STATEMENT}

The data used to support the findings of this study are available from the corresponding author upon request.

\section{CONFLICT OF INTEREST}

The authors declare that there is no conflict of interests regarding the publication of this paper.

\section{FUNDING}

We have received no source of funding that supports this

study.

\section{PUBLISHER'S NOTE}

This journal remains neutral with regard to jurisdictional claims in published institutional affiliation.

\section{REFERENCES}

Barouaca H. Malnutrition in Moroccan children: what results after 40 years of struggle? Nutr Clín Diet Hosp, 2012; 32(Supl. 2):76-81.

Becker PJ, Carney LN, Corkins MR, Monczka J, Smith E, Smith SE, Spear BA, White JV. Consensus statement of the academy of nutrition and dietetics/American society for parenteral and enteral nutrition: indicators recommended for the identification and documentation of pediatric malnutrition (undernutrition). J Acad Nutr Diet, 2014; 114(12):1988-2000.

Bélanger V, McCarthy A, Marcil V, Marchand V, Boctor DL, Rashid M, Noble A, Avinashi V, Davidson B, Groleau V, Spahis S, Levy E. Assessment of malnutrition risk in Canadian pediatric hospitals: a multicenter prospective cohort study. J Pediatr, 2019; 205(e6):160-7.

Bilukha O, Leidman E. Concordance between the estimates of wasting measured by weight-for-height and by mid-upper arm circumference for classification of severity of nutrition crisis: analysis of population-representative surveys from humanitarian settings. BMC Nutr, 2018; 4:24.

Black RE, Victora CG, Walker SP, Bhutta ZA, Christian P, de Onis M, Ezzati M, Grantham-McGregor S, Katz J, Martorell R, Uauy R, Maternal and Child Nutrition Study Group. Maternal and child undernutrition and overweight in low-income and middle-income countries. Lancet, $2013 ; 382: 427-51$.

Chiabi A, Malangue B, Nguefack S, Dongmo FN, Fru F, Takou $\mathrm{V}$, Angwafo $\mathrm{F}$. The clinical spectrum of severe acute malnutrition in children in Cameroon: a hospital-based study in Yaounde, Cameroon. Transl Pediatr, 2017; 6(1):32-9.

Cohen J. Weighted kappa: nominal scale agreement with provision for scaled disagreement or partial credit. Psychol Bull, 1968; 70:213-20.

Daskalou E, Galli-Tsinopoulou A, Karagiozoglou-Lampoudi T, Augoustides-Savvopoulou P. Malnutrition in hospitalized pediatric patients: assessment, prevalence, and association to adverse outcomes. J Am Coll Nutr, 2016; 35(4):372-80.

De Onis M (2015). World Health Organization Reference Curves. In M.L. Frelut (Ed.), The ECOG's eBook on Child and Adolescent Obesity. Retrieved from ebook.ecog-obesity.eu. 2015. Available via https:// ebook.ecog-obesity.eu/wp-content/uploads/2015/02/ECOG-ObesityeBook-World-Health-Organization-Reference-Curves.pdf

Doğan Y, Erkan T, Sema Y, Altay S, Cokuğraș FC, Aydin A, Kutlu T. Nutritional status of patients hospitalized in pediatric clinic. Turk J Gastroenterol, 2005; 16(4):212-6.

Dukhi N, Sartorius B, Taylor M. Mid-upper arm circumference (MUAC) performance versus weight for height in South African children
(0-59 months) with acute malnutrition. S Afr J Clin Nutr, 2017; 30(2):4954.

ENPSF. Enquête Nationale sur la Population et la Santé Familiale. Ministère de la Santé Publique, Royaume du Maroc, 2018.

Fiorentino M, Sophonneary P, Laillou A, Whitney S, de Groot R, Perignon $\mathrm{M}$, et al. Current MUAC cut-offs to screen for acute malnutrition need to be adapted to gender and age: the example of Cambodia. PLoS One, 2016; 11(2):e0146442.

Furlong KR, Anderson LN, Kang H, Lebovic G, Parkin PC, Maguire JL, O'Connor DL, Birken CS. BMI-for-age and weight-for-length in children 0 to 2 years. Pediatrics, 2016; 138(1):e20153809.

Grellety E, Golden MH. Weight-for-height and mid-upper arm circumference should be used independently to diagnose acute malnutrition: policy implications. BMC Nutr, 2016; 2:10.

Hankard R, Bloch J, Martin P, Randrianasolo H, Bannier MF, Machinot S, Cézard JP. Nutritional status and risk in hospitalized children. Arch Pediatr, 2001; 8:1203-8.

Hanley JA, McNeil BJ. The meaning and use of the area under a receiver operating characteristic (ROC) curve. Radiology, 1982; 143(1):2936.

Hosmer DW, Lemeshow S. Applied logistic regression. 2nd edition, Chapter 5, John Wiley and Sons, New York, NY, pp 160-4, 2000.

Hossain MI, Ahmed T, Arifeen SE, Billah SM, Faruque A, Islam $\mathrm{MM}$, Jackson AA. Comparison of midupper arm circumference and weightfor-height zscore for assessing acute malnutrition in Bangladeshi children aged 6-60 mo: an analytical study. Am J Clin Nutr, 2017; 106(5):1232-7.

Joosten KFM, Hulst JM. Malnutrition in pediatric hospital patients: current issues. Nutrition, 2011;27:133-7.

Landis JR, Koch GG. The measurement of observer agreement for categorical data. Biometrics, 1977; 33(1):159-74.

Leidman E, Couture A, Hulland E, Bilukha O. Concordance between estimates of acute malnutrition measured by weight-for-height and by mid-upper arm circumference after age adjustment: populationrepresentative surveys from humanitarian settings. BMC Nutr, 2019; 5:39.

Marginean O, Pitea AM, Voidazan S, Marginean C. Prevalence and assessment of malnutrition risk among hospitalized children in Romania. J Health Popul Nutr, 2014; 32(1):97-102.

McCarthy A, Delvin E, Marcil V, Belanger V, Marchand V, Boctor D, Rashid M, Noble A, Davidson B, Groleau V, Spahis S, Roy C, Levy E. Prevalence of malnutrition in pediatric hospitals in developed and in-transition countries: the impact of hospital practices. Nutrients, 2019; 11(2):236

Mehta NM, Corkins MR, Lyman B, Malone A, Goday PS, Carney LN, Monczka JL, Plogsted SW, Schwenk WF, American Society for Parenteral and Enteral Nutrition Board of Directors. Defining pediatric malnutrition: a paradigm shift toward etiology-related definitions. JPEN J Parenter Enteral Nutr, 2013; 37(4):460-81.

Meijers JMM, Marian AE van Bokhorst-de van der Schueren, Schols JMGA, Soeters PB, Halfens RJG. Defining malnutrition: mission or mission impossible? Nutrition, 2010; 26(4):432-40.

MIDGCL. La Région de Drâa-Tafilalet. Monographie Generale. MIDGCL, Royaume du Maroc, 2015. Available via http://www.fcs.ma/ wp-content/uploads/2016/12/MONOGRAPHIE-DE-LA-REGION-DEDRAA-TAFILALET-FR.pdf

Ministère de la Santé. Etat de santé population marocaine. Ministère de la Santé, Rabat, Morocco, 2012.

Ministère de la Santé. Royaume du Maroc: Stratégie National de nutrition 2011-2019. Ministère de la Santé, Rabat, Morocco, 2011.

Moy RJD, Smallmann S, Booth IW. Malnutrition in a UK children's hospital. J Hum Nutr Diet, 1990; 3:93-100.

Müller $\mathrm{O}$, and Krawinkel M. Malnutrition and health in developing countries. CMAJ, 2005 Aug 2; 173(3): 279-286.

Ng M, Fleming T, Robinson M, Thomson B, Graetz N, Margono C, Mullany EC, Biryukov S, Abbafati C, Abera SF, Abraham JP, AbuRmeileh NME, Achoki T, AlBuhairan FS, Alemu ZA, Alfonso R, Ali MK, Ali R, Guzman NA, Ammar W, Anwari P, Banerjee A, Barquera S, 
Basu S, Bennett DA, Bhutta Z, Blore J, Cabral N, Nonato IC, Chang JC, Chowdhury R, Courville KJ, Criqui MH, Cundiff DK, Dabhadkar KC, Dandona L, Davis A, Dayama A, Dharmaratne SD, Ding EL, Durrani AM, Esteghamati A, Farzadfar F, Fay DFJ, Feigin VL, Flaxman A, Forouzanfar MH, Goto A, Green MA, Gupta R, Hafezi-Nejad N, Hankey GJ, Harewood HC, Havmoeller R, Hay S, Hernandez L, Husseini A, Idrisov BT, Ikeda N, Islami F, Jahangir E, Jassal SK, Jee SH, Jeffreys M, Jonas JB, Kabagambe EK, Khalifa SEAH, Kengne AP, Khader YS, Khang YH, Kim D, Kimokoti RW, Kinge JM, Kokubo Y, Kosen S, Kwan G, Lai T, Leinsalu M, Li Y, Liang X, Liu S, Logroscino G, Lotufo PA, Lu Y, Ma J, Mainoo NK, Mensah GA, Merriman TR, Mokdad AH, Moschandreas J, Naghavi M, Naheed A, Nand D, Venkat Narayan KM, Nelson EL, Neuhouser ML, Nisar MI, Ohkubo T, Oti SO, Pedroza A, Prabhakaran D, Roy N, Sampson U, Seo H, Sepanlou SG, Shibuya K, Shiri R, Shiue I, Singh GM, Singh JA, Skirbekk V, Stapelberg NJC, Sturua L, Sykes BL, Tobias M, Tran BX, Trasande L, Toyoshima H, van de Vijver S, Vasankari TJ, Veerman JL, VelasquezMelendez G, Vlassov VV, Vollset SE, Vos T, Wang C, Wang XR, Weiderpass E, Werdecker A, Wright JL, Yang YC, Yatsuya H, Yoon J, Yoon SJ, Zhao Y, Zhou M, Zhu S, Lopez AD, Murray CJL, Gakidou E. Global, regional, and national prevalence of overweight and obesity in children and adults during 1980-2013: a systematic analysis for the Global Burden of Disease Study 2013. Lancet, 2014; 384:766-81.

Öztürk Y, Büyükgebiz B, Arslan N, Ellidokuz H. Effects of hospital stay on nutritional anthropometric data in Turkish children. J Trop Pediatr, 2003; 49:189-90.

Parikh R, Mathai A, Parikh S, Sekha GC, Thomas R. Understanding and using sensitivity, specificity and predictive values. Indian J Ophthalmol, 2008; 56(1):45-50.

Pawellek I, Dokoupil K, Koletzko B. Prevalence of malnutrition in paediatric hospital patients. Clin Nutr, 2008; 27:72-6.

Sachdeva S, Dewan P, Shah D, Malhotra RK, Gupta P. Midupper arm circumference $\mathrm{v}$. weight-for-height Z-score for predicting mortality in hospitalized children under 5 years of age. Public Health Nutr, 2016; 19(14):2513-20.

Sissaoui S, De Luca A, Piloquet H, Guimber D, Colomb V, Peretti N, Bouniol A, Breton A, Chouraqui JP, Coste ME, Djeddi D, Dorigny B, Goulet O, Gottrand F, Hermouet P, Lambe C, Leke A, Leprince S, Mas E, Massicot P, Renard P, Thomassin N, Triolo V, Turquet A, Vanrenterghem A, Fischbach M, Ingrand P, Hankard R. Large scale nutritional status assessment in pediatric hospitals. ESPEN J, 2013; 8:e68-72.

Tadesse AW, Tadesse E, Berhane Y, Ekström EC. Comparison of mid-upper arm circumference and weight-for-height to diagnose severe acute malnutrition: a study in Southern Ethiopia. Nutrients, 2017; 9(3):267.
Tessema M, Laillou A, Tefera A, Teklu Y, Berger J, Wieringa FT. Routinely MUAC screening for severe acute malnutrition should consider the gender and age group bias in the Ethiopian non-emergency context PLoS One, 2020; 15(4):e0230502.

WHO. Guideline: updates on the management of severe acute malnutrition in infants and children. World Health Organization, Geneva, Switzerland, 2013.

WHO. Physical status: the use and interpretation of anthropometry. Report of a WHO Expert Committee. Technical Report Series No. 854. World Health Organization, Geneva, Switzerland, 1995.

WHO. WHO child growth standards: length/height-for-age, weight-for-age, weight-for-length, weight-for-height and body mass indexfor-age (BMI-Z): methods and development. World Health Organization, Geneva, Switzerland, 2006.

Wieringa FT, Gauthier L, Greffeuille V, Som SV, Dijkhuizen MA, Laillou A, Chamnan C, Berger J, Poirot E. Identification of acute malnutrition in children in Cambodia requires both mid upper arm circumference and weight-for-height to offset gender bias of each indicator. Nutrients, 2018; 10(6):786.

World Health Organization, United Nations Children's Fund (UNICEF). Recommendations for data collection, analysis and reporting on anthropometric indicators in children under 5 years old. WHO, UNICEF, Geneve, Switzerland, 2019.

World Medical Association. Declaration of Helsinki ethical principles for medical research involving human subjects. JAMA, 2013; 310(20):2191-4.

Zong X, Li H, Zhang Y, Wu H. Weight-for-length/height growth curves for children and adolescents in China in comparison with body mass index in prevalence estimates of malnutrition. Ann Hum Biol, 2017; 44(3):214-22.

Zweig MH, Campbell, G. Receiver-operating characteristic (ROC) plots: a fundamental evaluation tool in clinical medicine. Clin Chem, 1993; 39:561-77.

\section{How to cite this article:}

Barouaca H, Ben Loubir D, El Bouhali B, Tachfouti N, El Midaoui A. The role of body mass index-for-age in the assessment of acute malnutrition and obesity in Moroccan hospitalized children. J Appl Pharm Sci, 2021; 11(07): 098-104 